\title{
Surface roughness evaluation of various cutting materials in hard turning of AISI H11
}

\author{
H. Aouici ${ }^{a}$, B. Fnides ${ }^{b}$, M. Elbah ${ }^{c}$, S. Benlahmidi ${ }^{a}$,H. Bensouilah ${ }^{a}$ and M. A. Yallese ${ }^{a}$
}

${ }^{a}$ Laboratoire Mécanique et Structures (LMS), Département de Génie Mécanique, FST, Université 08 Mai 1945, Guelma 24000, Algérie

${ }^{b}$ ENST-ex CT siège DG. SNVI, Route Nationale $N^{\circ} 5$ Z. I.16012, Rouiba, Algérie

'Département de Construction Mécanique et Productique, FGM\&GP, USTHB, BP 32 El-Alia, Bab-Ezzouar, 16111, Alger, Algérie

\section{H R O N I C L E A B S T R A C T}

Article history:

Received July 212015

Received in Revised Format

August 162015

Accepted September 12015

Available online

September 42015

\section{Keywords:}

Hard turning

AISI H11 steel

Ceramic

$C B N$

ANOVA

$R S M$

\begin{abstract}
This paper describes a comparison of surface roughness between ceramics and cubic boron nitride (CBN7020) cutting tools when machining of AISI H11 hot work steels treated at 50 HRC. Plan is designed according to Taguchi's L18 $(21 \times 32)$ orthogonal array. The response surface methodology (RSM) and analysis of variance (ANOVA) were used to check the validity of multiple linear regression models and to determine the effects, contribution, significance and optimal machine settings of process parameters, namely, cutting speed, feed rate and depth of cut on machining parameters on the Ra and Rt. The results of this research work showed that, the feed rate was found to be a dominant factor on the surface roughness, followed by the cutting speed, lastly the depth of cut. The CBN7020 cutting tool showed the better performance than that of ceramic based cutting tool. In addition, the combination of low feed rate and high cutting speed is necessary for minimizing the surface roughness.
\end{abstract}

C) 2016 Growing Science Ltd. All rights reserved

\section{Introduction}

In turning, the machining operation is achieved by using purposely developed cutting tool materials, such as ceramics and cubic boron nitride $(\mathrm{CBN})$. The latter presents a unique property combination between hardness, good resistance at high temperature and thermo-chemical stability. These properties are strongly required in cutting tool materials when machining hard ferrous workpieces. Moreover, the reliability improvement of the ceramics and CBN cutting tools generated the hard turning; a machining process with significant importance in manufacture. Although it is well applied in machining shafts, bearings, pinions, cams and other mechanical components there is a need of research to improve performance of ceramics and $\mathrm{CBN}$ tools by taking into account the choice of the machining systems (Bouchelaghem et al., 2010; Fnides et al., 2011). 
In recent years, there are performed various statistical and experimental studies which are based on design and analysis of experiment methods to determine the effects of cutting parameters on the surface roughness occurred in hard/finish turning of various materials. The work of Sahin and Motorcu (2008) presents experimental investigated the surface roughness of AISI 1050 steel that was machined by turning with cubic boron nitride (CBN) and ceramic cutting tools. They determined that the feed rate is the most effective parameter on the average surface roughness $(R a)$ by using response surface methodology (RSM). They obtained a $0.823 \mu \mathrm{m} R a$ value with CBN tool when turning a 484 Hardness Vickers (HV) hardness workpiece. Aouici et al. (2012) investigated the effects of cutting speed, feed rate, workpiece hardness and depth of cut on surface roughness and cutting force components in hard turning. AISI H1 1 steel, hardened to 40, 45 and $50 \mathrm{HRC}$, respectively, was machined using cubic boron nitride tools. Mathematical models were developed for surface roughness and cutting force components using the response surface methodology (RSM). Results showed that the cutting force components were influenced principally by depth of cut and workpiece hardness; however, both feed rate and workpiece hardness had statistical significance on surface roughness. Thiele and Melkote (1999) carried out an experimental investigation of effects of workpiece hardness and tool edge geometry on surface roughness in finish hard turning using CBN tools. They applied an analysis of variance (ANOVA) to the experimental results in order to distinguish whether differences in surface quality for various runs were statistically important. Horng et al. (2008) presented a model to evaluate the machinability of Hadfield steel by applying RSM and Analysis of Variance (ANOVA) techniques. Kribes et al. (2012) performed statistical analysis to study the influence of cutting speed, feed rate and depth of cut on surface roughness in hard turning of $42 \mathrm{CrMo} 4$ steel with coated mixed ceramics inserts.

The aim of the work reported in Asiltürk and Neseli (2011), was to model the surface roughness in turning of AISI 304 austenitic stainless steel under dry conditions, using the Response Surface Methodology (RSM). An orthogonal array was applied to study the influence of cutting parameters (cutting speed, feed rate and depth of cut) on the surface roughness.

Few work shave compared the performance of various tool materials during hard turning (Sales et al., 2009; Mahfoudi et al., 2008). While comparing the tool life of ceramics and CBN tools when machining hardened steels, results showed that cutting velocity is predominant factor for tool wear followed by tool hardness. Feed has the least effect on tool wear (Sales et al., 2009). CBN inserts show better performance than the ceramics. When comparing performance of coated cemented carbide, mixed ceramics and PCBN-H tools while turning W320 steel (Mahfoudi et al., 2008), experiments showed that cemented carbides performed better at speeds up to $120 \mathrm{~m} / \mathrm{min}$ while $\mathrm{CBN}$-(High) tools are superior at high cutting speeds (up to $200 \mathrm{~m} / \mathrm{min}$ ). Mixed ceramics did not perform well. Adhesion, abrasion and plastic deformation were dominant wear mechanisms, although chipping on the rake and flank faces and catastrophic failure were also observed in some experiments .CBN at low speeds are susceptible to high wear promoted due to chipping.

Recently, Elbah et al. (2013) applied response surface methodology (RSM) and ANOVA to compere the machinability of hardened AISI 4140 cold work tool steel wiper and conventional ceramics (CC6050WH and CC6050). The results indicated that surface roughness of 4140 steel was improved as cutting speed was elevated and deteriorated with feed rate. However, the surface quality obtained with the wiper ceramic insert allowed a surface finish as good when compared with conventional ceramic insert is 2.5 . Fnides et al. (2013) investigated the productivity in terms of volume chip carved of six cutting tools for two different cutting conditions in straight hard turning of X38CrMoV5-1 (50 HRC). They found that for the first cutting regime $(V c=120 \mathrm{~m} / \mathrm{min}, a p=0.15 \mathrm{~mm}$ et $f=0.08 \mathrm{~mm} / \mathrm{rev})$, the productivity of the uncoated cermets CT5015, the coated cermets GC1525, the uncoated carbide H13A, the reinforced ceramic CC670, the coated carbide GC3015 and the mixed ceramic CC650 are $(2160 ; 1440 ; 6480 ; 11520$; 23040 and 70560) $\mathrm{mm}^{3}$, respectively. The productivity of these three selected tools, i.e. mixed ceramic CC650, reinforced ceramic CC670 and coated carbide GC3015 for the second cutting regime $(f=0.08$ $\mathrm{mm} / \mathrm{rev}, a p=0.15 \mathrm{~mm}$ and $\left.V_{c}=90 \mathrm{~m} / \mathrm{min}\right)$ are $(85860 ; 12960$ and 30780$) \mathrm{mm}^{3}$, respectively. Their results prove that the mixed ceramic $\mathrm{Al}_{2} \mathrm{O}_{3}+\mathrm{TiC}$ (CC650) is more efficient than other tools used in terms of productivity. 
In the work of Davim and Figueira (2007), performed statistical analysis to study the influence of cutting speed and feed rate on flank wear, specific cutting pressure, and surface roughness in hard turning of AISI D2 cold work tool steel with conventional ceramic inserts. Their results prove that the wiper ceramic cutting tool CC650WG has the better performance compared with traditional ceramic cutting tools CC650, in particular the surface roughness of the workpiece. In another studies, Federico et al. (2008) performed turning of hardened steel using $\mathrm{TiCN} / \mathrm{Al}_{2} \mathrm{O}_{3} / \mathrm{TiN}$ coated carbide and PCBN tools, respectively. The results concluded that machining of medium hardened steels was productive with $\mathrm{TiCN} / \mathrm{Al}_{2} \mathrm{O}_{3} / \mathrm{TiN}$ coated carbide tools. Lima et al. (2005) investigated the machinability of hardened steels AISI 4340 and AISI D2 with different of hardness values, using various cutting tool materials. The results indicated that when turning AISI 4340 steel the surface roughness improved with cutting velocity and increases is deteriorated when feed rate increases. Depth of cut presents little effect on the surface roughness values. Gaitonde et al. (2009) revealed that, wiper insert performed better with reference to surface roughness and tool wear, while the conventional insert is useful in reducing the machining force, power and specific cutting force during turning of high chromium AISI D2 cold work tool steel with ceramic inserts. Okada et al. (2011) have investigated cutting performance of CBN tools and PVD-coated carbide tools in endmilling of hardened steel. In this study, the influence of workpiece hardness on surface roughness was summarized.

\section{Experimental works}

\subsection{Work piece material, machine and tool}

Round bars with $75 \mathrm{~mm}$ diameter and $400 \mathrm{~mm}$ length were used as work piece materials. The workpiece material was AISI H1 1, hot work steel which is popularly used in hot form pressing. Its resistance to high temperature and its aptitude for polishing enable it to answer most requests for hot dieing and molding under pressure. Its chemical composition (in wt.\%) are given as: $\mathrm{C} 0.35$; $\mathrm{Cr} 5.26$; Mo 1.19; V 0.50; Si 1.01; Mn 0.32; S 0.002; P 0.016; Fe 90.31 and other components 1.042. It is hardened to $50 \mathrm{HRC}$. Its hardness was measured by a digital durometer DM2D. Turning experiments were performed in dry conditions using a universal lathe type SN 40C with $6.6 \mathrm{~kW}$ spindle power. The cutting inserts used are reinforced ceramic CC670, mixed ceramic CC650, and cubic boron nitride CBN7020 (Fig. 1). These inserts are removable, of square form with eight cutting edges. Their characteristics are shown in Table 1.

Table 1

Characteristics of used inserts (Çiçek et al. 2013)

\begin{tabular}{llcccc}
\multicolumn{1}{c}{ Cutting materials } & Designation & Chemical composition & $\begin{array}{c}\text { Hardness } \\
(\mathrm{HV})\end{array}$ & $\begin{array}{c}\text { Thermal } \\
\text { conductivity } \\
\left(\mathrm{Wm}^{-1} \mathrm{~K}^{-1}\right)\end{array}$ \\
\hline Reinforced ceramic CC670 & SNGN120408 T 010 20 & $\mathrm{Al}_{2} \mathrm{O}_{3}(80 \%)+\mathrm{SiC}(20 \%)$ & $\sim 2000$ & $\sim 18$ \\
\hline Mixed ceramic CC650 & SNGA120408 T 010 20 & $\mathrm{Al}_{2} \mathrm{O}_{3}(70 \%)+\mathrm{TiC}(22.5 \%)$ & $\sim 1800$ & $\sim 24$ \\
\hline Cubic boron nitride CBN7020 & SNGA120408 S 010 20 & $\mathrm{CBN}(57 \%)+\mathrm{Ti}(\mathrm{C}, \mathrm{N})(35 \%)$ & $\sim 2800$ & $\sim 740$ \\
\hline
\end{tabular}

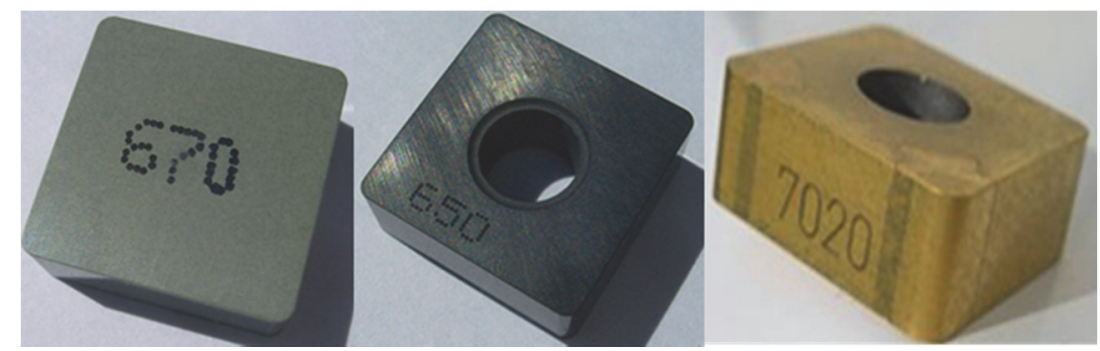

Fig. 1. Cutting tools: (a) CC650, (b) CC670 and (c) CBN7020 
The toolholders adapted are of designation CSBNR2525M12 and PSBNR2525M12 with geometry of the active part characterized by the following angles: $\chi=75^{\circ} ; \alpha=6^{\circ} ; \gamma=-6^{\circ} ; \lambda=-6^{\circ}$.

The test specimens have been hardened to the required hardness of $60 \mathrm{HRC}$ through quenching at $940^{\circ} \mathrm{C}$ and tempering at $280^{\circ} \mathrm{C}$. Its hardness was measured by a digital durometer (DM2-D 390). The all surface roughness measurements have been obtained directly on the tool machine and without disassembling the workpiece by means of roughness meter (Surftest 301 Mututoyo). Illustration of measured surface roughness is given in Fig. 2. The length examined was $2.4 \mathrm{~mm}$ with a basic span of 3. The measured values of $R a$ and $R t$ are within the range $0.05-40 \mu \mathrm{m}$. This roughness was directly measured on the workpiece, without dismounting from the lathe, in order to reduce uncertainties due to resumption operations. The measurements were repeated three times at three reference lines equally positioned at $120^{\circ}$.

\subsection{Design of experiments}

The aim of the experiments was to analyze the effects of cutting parameters on surface roughness during the hard turning of AISI H11. The experiments were carried out using full factorial method (Taguchi's L18), and results were analyzed with RSM. The RSM procedure is capable of determining a relationship between independent input process parameters and output data. This procedure includes 6 steps. These are, (1) defining the independent input variables and the desired output responses, (2) adopting an experimental design plan, (3) performing regression analysis with the multiple linear regression models of RSM, (4) calculating the ANOVA for the independent input variables in order to find parameters which significantly affect the response, (5) determining the situation of multiple linear regression models of RSM and finally, (6) optimizing, conducting confirmation experiment and verifying the predicted performance characteristics (Aouici et al. 2012). The selected cutting parameters were cutting speed, feed rate and depth of cut. Various levels of cutting parameters are given in Table 2. The results obtained from experiments without cutting fluid are presented in Table 3.

In the current study, the relationship between the input, called the cutting conditions (cutting speed $(V c)$, feed rate $(f)$ and depth of cut $(a p))$ and the output $Y$ define as a machinability aspect (surface roughness criteria $(R a$ and $R t))$ is given as :

$$
Y=\varphi\left(V_{c}, f, a p\right),
$$

where $\varphi$ is the response function. The approximation of $Y$ is proposed by using a multiple linear mathematical model, which is suitable for studying the interaction effects of process parameters on machinability characteristics. In the present work, the RMS based multiple linear mathematical model is given by:

$$
Y=a_{0}+\sum_{i=1}^{k} b_{i} X_{i}+\sum_{i, j}^{k} b_{i j} X_{i} X_{j}
$$

where $a_{0}$ is the free term of the regression equation, the coefficients $b_{1}, b_{2}, \ldots b_{k}$ are the linear; while $b_{12}, b_{13}, \ldots b_{k-1}$ are the interacting terms. $X i$ represents input parameters ( $V c, f$ and $\left.a p\right)$.

\section{Table 2}

Assignment of the factor levels

\begin{tabular}{cccc}
\hline Level & Cutting speed, $V c(\mathrm{~m} / \mathrm{min})$ & Feed rate, $f(\mathrm{~mm} / \mathrm{rev})$ & Depth of cut, ap $(\mathrm{mm})$ \\
\hline 1 & 120 & 0.08 & 0.15 \\
\hline 2 & 180 & 0.12 & 0.30 \\
\hline 3 & - & 0.16 & 0.45 \\
\hline
\end{tabular}




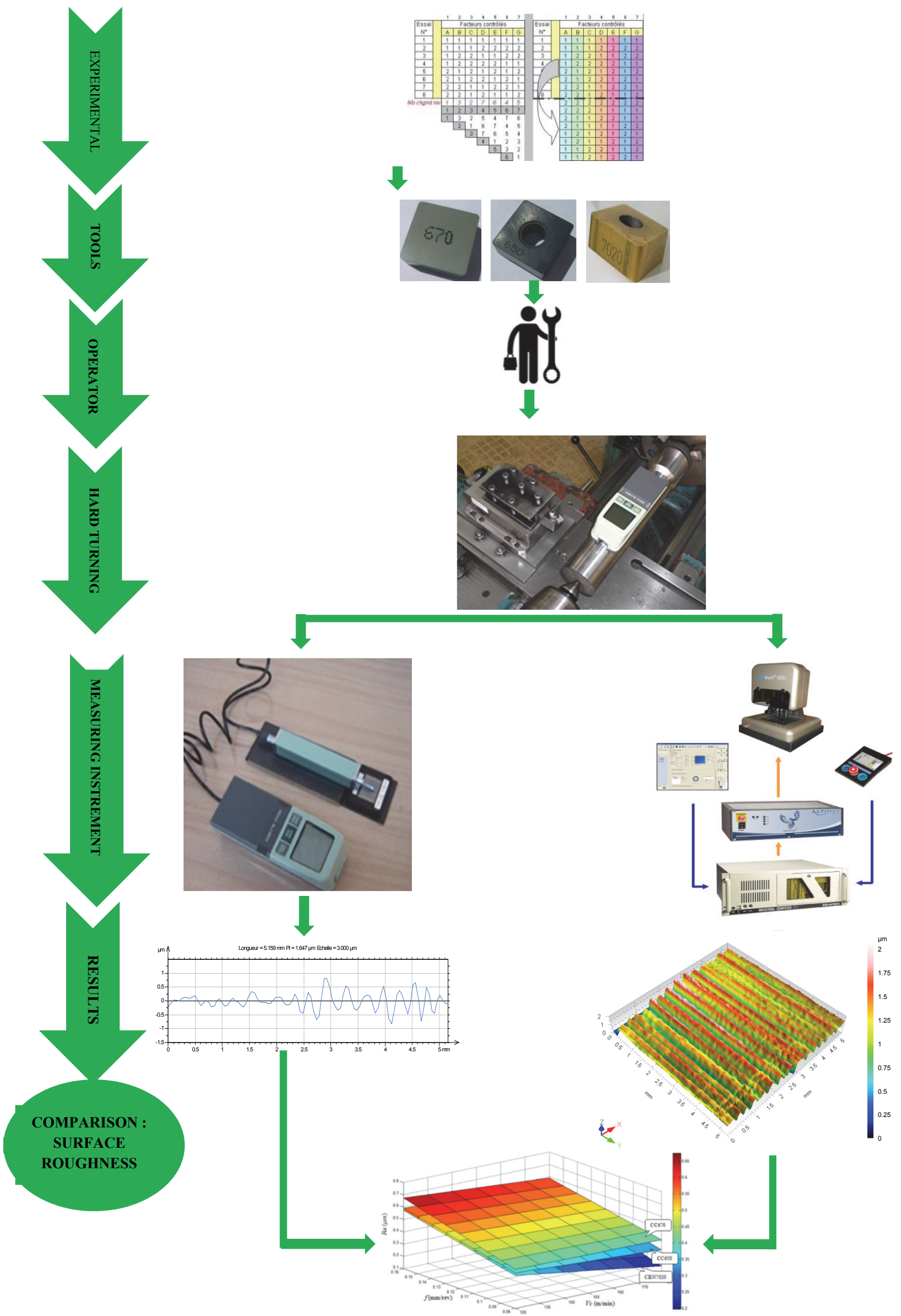

Fig. 2. Illustration of measured surface roughness criteria 


\section{Results and discussion}

Experimental matrix and results of surface roughness criteria when hard turning of AISI H11 hot work steel were analyzed for three different cutting tools, namely reinforced ceramic CC670, mixed ceramic CC650, and cubic boron nitride CBN7020; is shown in Table 3. Regression equations for arithmetic mean roughness $(R a)$ and total roughness $(R t)$ were developed based on experimental data. The values of the coefficients involved in the equation were calculated by regression method by using the Design Expert software. Equations developed for surface roughness criteria for different cutting tools are given below:

\section{Table 3}

$\underline{\mathrm{L}_{18}\left(2^{1} \times 3^{2}\right) \text { orthogonal array and experimental data }}$

\begin{tabular}{|c|c|c|c|c|c|c|c|c|c|}
\hline \multirow{3}{*}{ Test $\mathrm{N}^{\circ}$} & \multirow{2}{*}{\multicolumn{3}{|c|}{ Machining parameters }} & \multicolumn{6}{|c|}{ Response factors } \\
\hline & & & & \multicolumn{2}{|c|}{ CC670 } & \multicolumn{2}{|c|}{ CC650 } & \multicolumn{2}{|c|}{ CBN7020 } \\
\hline & $\begin{array}{c}V c \\
(\mathrm{~m} / \mathrm{min})\end{array}$ & $f(\mathrm{~mm} / \mathrm{rev})$ & $\begin{array}{c}a p \\
(\mathrm{~mm})\end{array}$ & $R a(\mu \mathrm{m})$ & $R t \quad(\mu \mathrm{m})$ & $R a(\mu \mathrm{m})$ & $R t \quad(\mu \mathrm{m})$ & $\begin{array}{c}R a \\
(\mu \mathrm{m})\end{array}$ & Rt $(\mu \mathrm{m})$ \\
\hline 1 & 120 & 0.08 & 0.15 & 0.440 & 2.70 & 0.350 & 3.32 & 0.350 & 2.00 \\
\hline 2 & 120 & 0.08 & 0.30 & 0.430 & 2.79 & 0.400 & 2.67 & 0.390 & 2.30 \\
\hline 3 & 120 & 0.08 & 0.45 & 0.420 & 2.81 & 0.410 & 3.07 & 0.300 & 1.80 \\
\hline 4 & 120 & 0.12 & 0.15 & 0.530 & 3.22 & 0.460 & 3.54 & 0.460 & 3.00 \\
\hline 5 & 120 & 0.12 & 0.30 & 0.490 & 3.30 & 0.490 & 3.59 & 0.495 & 2.85 \\
\hline 6 & 120 & 0.12 & 0.45 & 0.520 & 3.41 & 0.510 & 3.60 & 0.565 & 3.05 \\
\hline 7 & 120 & 0.16 & 0.15 & 0.690 & 4.79 & 0.560 & 3.75 & 0.560 & 3.70 \\
\hline 8 & 120 & 0.16 & 0.30 & 0.700 & 4.82 & 0.590 & 3.97 & 0.545 & 4.15 \\
\hline 9 & 120 & 0.16 & 0.45 & 0.680 & 4.90 & 0.620 & 4.16 & 0.565 & 3.05 \\
\hline 10 & 180 & 0.08 & 0.15 & 0.430 & 2.69 & 0.300 & 2.80 & 0.230 & 1.60 \\
\hline 11 & 180 & 0.08 & 0.30 & 0.430 & 2.75 & 0.330 & 2.82 & 0.210 & 1.50 \\
\hline 12 & 180 & 0.08 & 0.45 & 0.400 & 2.83 & 0.340 & 2.85 & 0.180 & 1.20 \\
\hline 13 & 180 & 0.12 & 0.15 & 0.510 & 3.18 & 0.430 & 3.36 & 0.360 & 2.20 \\
\hline 14 & 180 & 0.12 & 0.30 & 0.460 & 3.25 & 0.460 & 3.40 & 0.270 & 1.70 \\
\hline 15 & 180 & 0.12 & 0.45 & 0.470 & 3.33 & 0.470 & 3.41 & 0.340 & 2.20 \\
\hline 16 & 180 & 0.16 & 0.15 & 0.590 & 4.43 & 0.540 & 3.67 & 0.500 & 3.20 \\
\hline 17 & 180 & 0.16 & 0.30 & 0.570 & 4.56 & 0.560 & 3.76 & 0.475 & 2.35 \\
\hline 18 & 180 & 0.16 & 0.45 & 0.640 & 4.74 & 0.580 & 3.81 & 0.505 & 2.85 \\
\hline
\end{tabular}

\subsection{Effect of cutting parameters on arithmetic mean roughness ( $R a)$}

Surface roughness measurement is one of the most important requirements in many engineering applications, as it is considered an important index of product quality. In the turning operations, the surface roughness is mainly controlled by the cutting conditions. Fig. 3 depicts the interaction effects of depth of cut-feed rate, depth of cut-cutting speed and feed rate-cutting speed on arithmetic mean roughness during hard turning of hot work steel using three different cutting tools at two levels of cutting speed and three levels of feed rate and depth of cut, respectively. According to the Fig. 3a, it can be seen that $R a$ increases with feed rate and better with cutting speed at $V c=180 \mathrm{~m} / \mathrm{min}$. The evolution of $R a$ with depth of cut shows that this parameter has a very weak effect compared to that of the feed rate. This is due to the increased length of contact between the tool and the workpiece. This improves the conditions of heat flow from the cutting zone and consequently slows down the process wear (Aouici et al., 2014).

As seen from Fig. $3 \mathrm{~b}$ that $R a$ value increases when the feed rate is increased from $0.08 \mathrm{~mm} / \mathrm{rev}$ to 0.16 $\mathrm{mm} / \mathrm{rev}$. This result shows that the need to choose lower feed rate is revealed to obtain small values of $R a$ during machining of hard materials such as AISI H11, particularly. It can be seen from Fig. $3 \mathrm{c}$ that $R a$ value increases linearly as the feed rate is increased from $0.08 \mathrm{~mm} / \mathrm{rev}$ to $0.16 \mathrm{~mm} / \mathrm{rev}$ when machining of AISI H11 with $50 \mathrm{HRC}$. On the other hand, it was determined that the $R a$ values obtained by the CBN7020 cutting tool at all cutting conditions, except $120 \mathrm{~m} / \mathrm{min}$ cutting speed, $0.12 \mathrm{~mm} / \mathrm{rev}$ feed rate and $0.45 \mathrm{~mm}$ depth of cut are lower. In general the CBN7020 tool produces a better surface finish 
compared with CC650 and CC670 inserts when machining of AISI H11 with 50 HRC. Table 4 shows the results of analysis of variance (ANOVA) for arithmetic mean roughness of CC670, CC650 and CBN7020 tools. The analysis is carried out for a significance level $\alpha=0.5$, (i.e. for a confidence level of $95 \%$ ). In this table, the degrees of freedom (DF), sum of squares (SCsq.), mean square (MS), F-values and probabilities (P-value), in addition to the contribution (Cont. \%) of each factor, are also shown. From Table 4, it can be seen that the feed rate (Cont. $\approx 90.62$; Cont. $\approx 90.01$ and Cont. $\approx 69.28$ ) $\%$ followed by cutting speed (Cont. $\approx 5.55$; Cont. $\approx 4.97$ and Cont. $\approx 28.00) \%$ had the greatest influence on tools CC670, CC650 and CBN7020, respectively. The depth of cut (Cont. $\approx 0.19$ and Cont. $\approx 0.01) \%$ does not present a statistically significant effect on arithmetic mean roughness for reinforced ceramic CC670 and cubic boron nitride CBN7020 respectively.
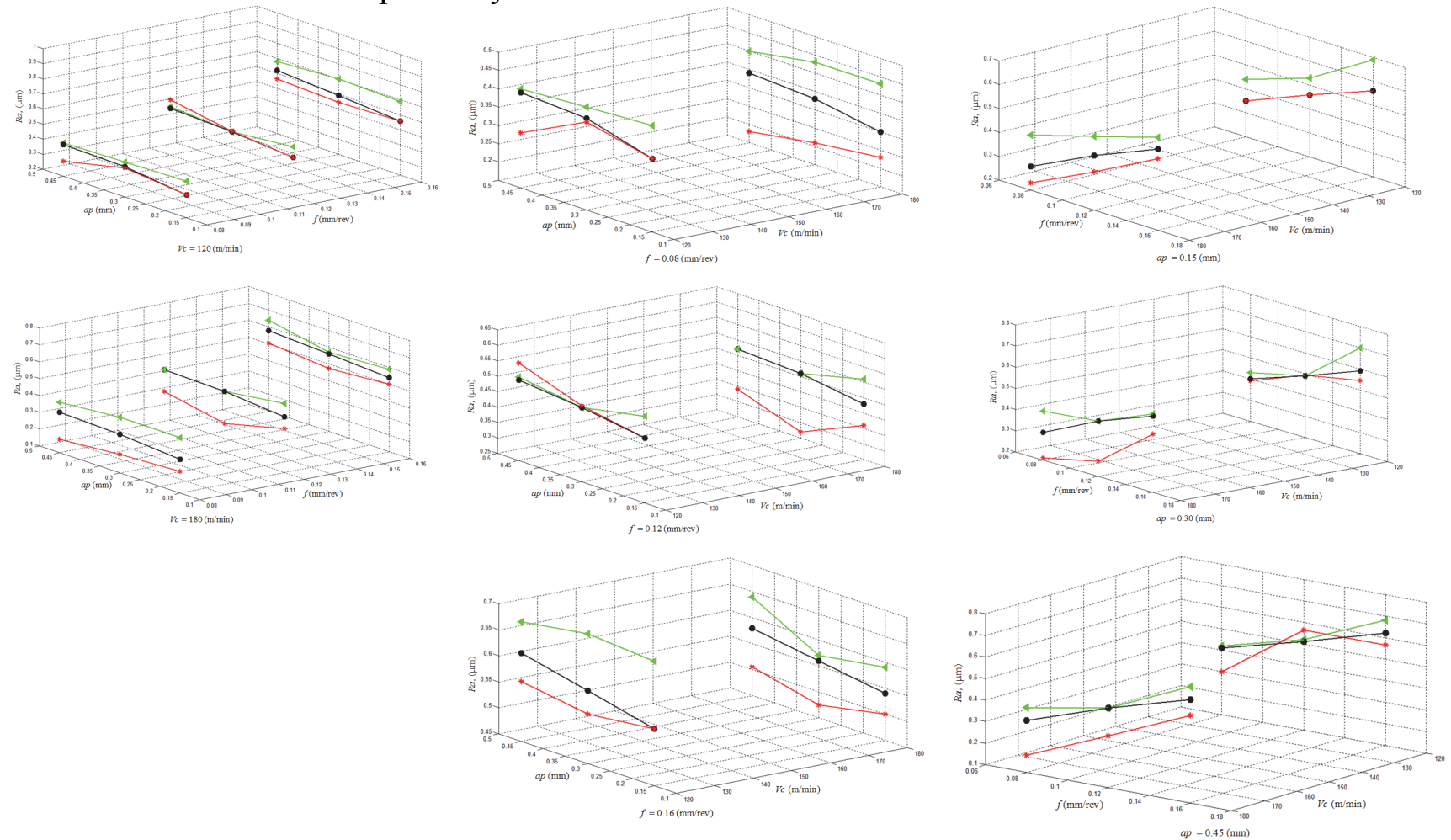

(a)

(b)

(c)

\section{CC7020}

CC650

CC670

Fig. 3. Effect of cutting conditions on arithmetic mean roughness for (CC670, CC650 and CBN7020)

\subsection{Effect of cutting parameters on total roughness (Rt)}

Fig. 4 shows the interaction effects of depth of cut-feed rate, depth of cut-cutting speed and feed ratecutting speed on total roughness during hard turning of hot work steel using three different cutting tools namely, reinforced ceramic CC670, mixed ceramic CC650 and cubic boron nitride CBN7020; at two levels of cutting speed and three levels of feed rate and depth of cut, respectively.

Fig. 4a shows the variation of the total roughness versus the depth of cut and feed rate at two levels of cutting speed. Rt values increase when the feed rate increases for third cutting tool materials, because its increase generates helicoid furrows, the result of tool shape and helicoid movement tool-workpiece. These furrows are deeper and broader as the feed rate increases. However, a qualitative comparison can be made; for example, Elbah et al. (2013) found that the feed rate is the important factor affecting surface roughness. For this reason, weak feed rate have to be employed during turning operation. As can be seen clearly in Fig. 2a, there is a regular interaction between the factors and the total roughness. From Fig. 4b 
illustrates the evolution of the total roughness according to the depth of cut and cutting speed at three levels of feed rate; $0.08,0.12$ and $0.16 \mathrm{~mm} / \mathrm{rev}$, it can be observed that, total roughness is lowly sensitive with to depth of cut at the all values of feed rate or cutting speed. Similar results were reported by Azizi et al. (2012) during hard turning of AISI 52100 steel with ceramic tool. From Figure 4c illustrates the evolution of the specific cutting force according to the depth of cut and feed rate, specific cutting force decreases with increase in depth of cut and feed rate. The variation of feed rate with cutting speed at three levels of depth of cut on total roughness is presented in Fig. 4c. The comparison reveals that, in case of CC670 reinforced ceramic insert, the total roughness is highly sensitive to feed rate as compared to CC650 and CBN720. In general, it can be concluded that the feed rate exhibits maximum influence on total roughness as compared to depth of cut and cutting speed.

Table 5 presents ANOVA results for Rt. It can be seen that the feed rate is the most important factor affecting surface finish $R t$. Its contribution is $(98.34 ; 90.63$ and 68.31) \% respectively; (CC670, CC650 and CBN7020) to these models. The second factor influencing $R t$ is cutting speed. Its contribution is (6.28 and 28.98) \% respectively (CC650 and CBN7020). The effect of the depth of cut is not significant because its contribution is $(0.74 ; 0.63$ and 2.07$) \%$ respectively; (CC670, CC650 and CBN7020) to these models.
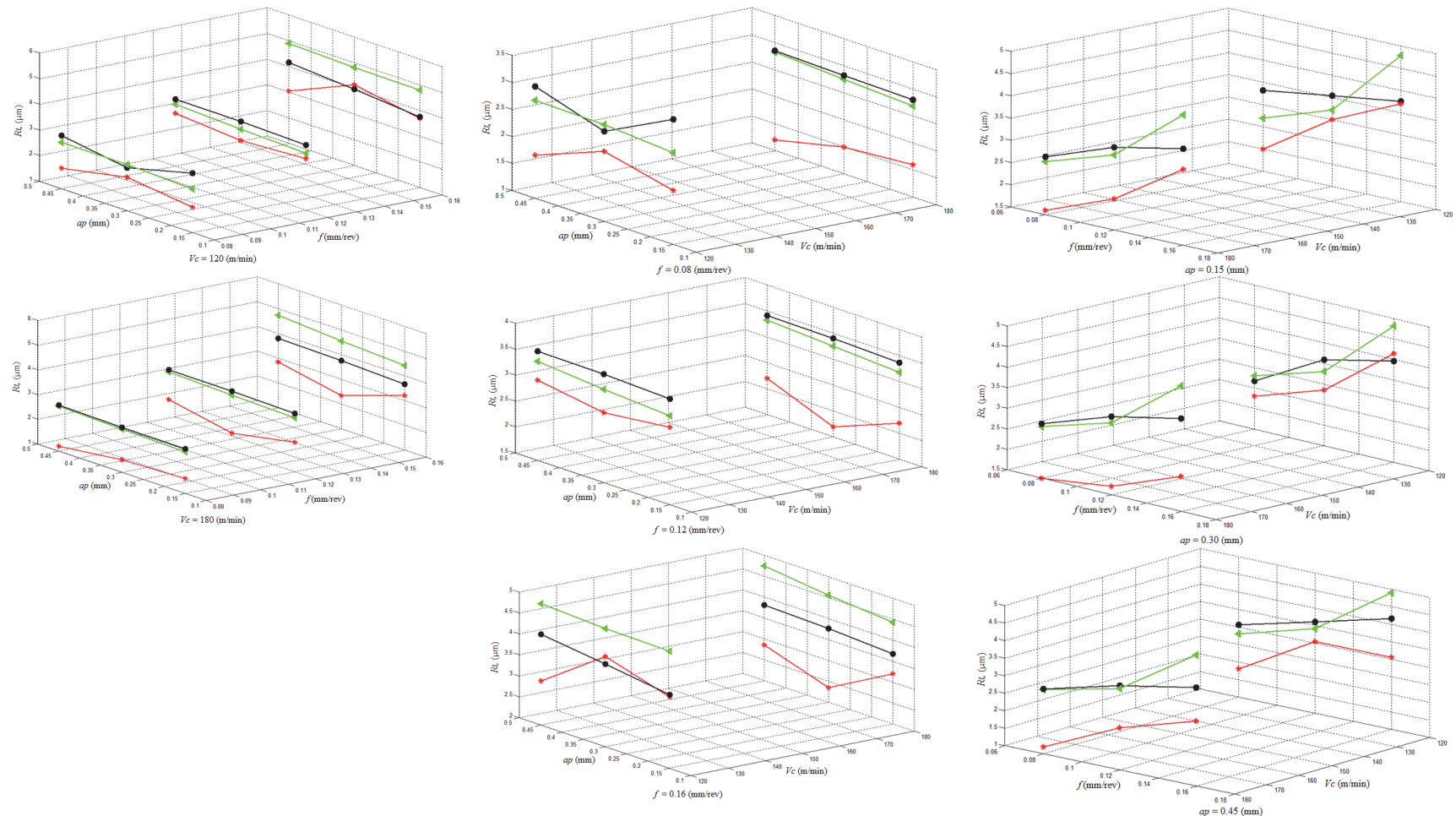

(a)

(b)

(c)

\section{CC7020}

CC650

CC670

Fig. 4. Effect of cutting conditions on total roughness for (CC670, CC650 and CBN7020) 
Table 4

Analysis of variance for surface roughness $R a$

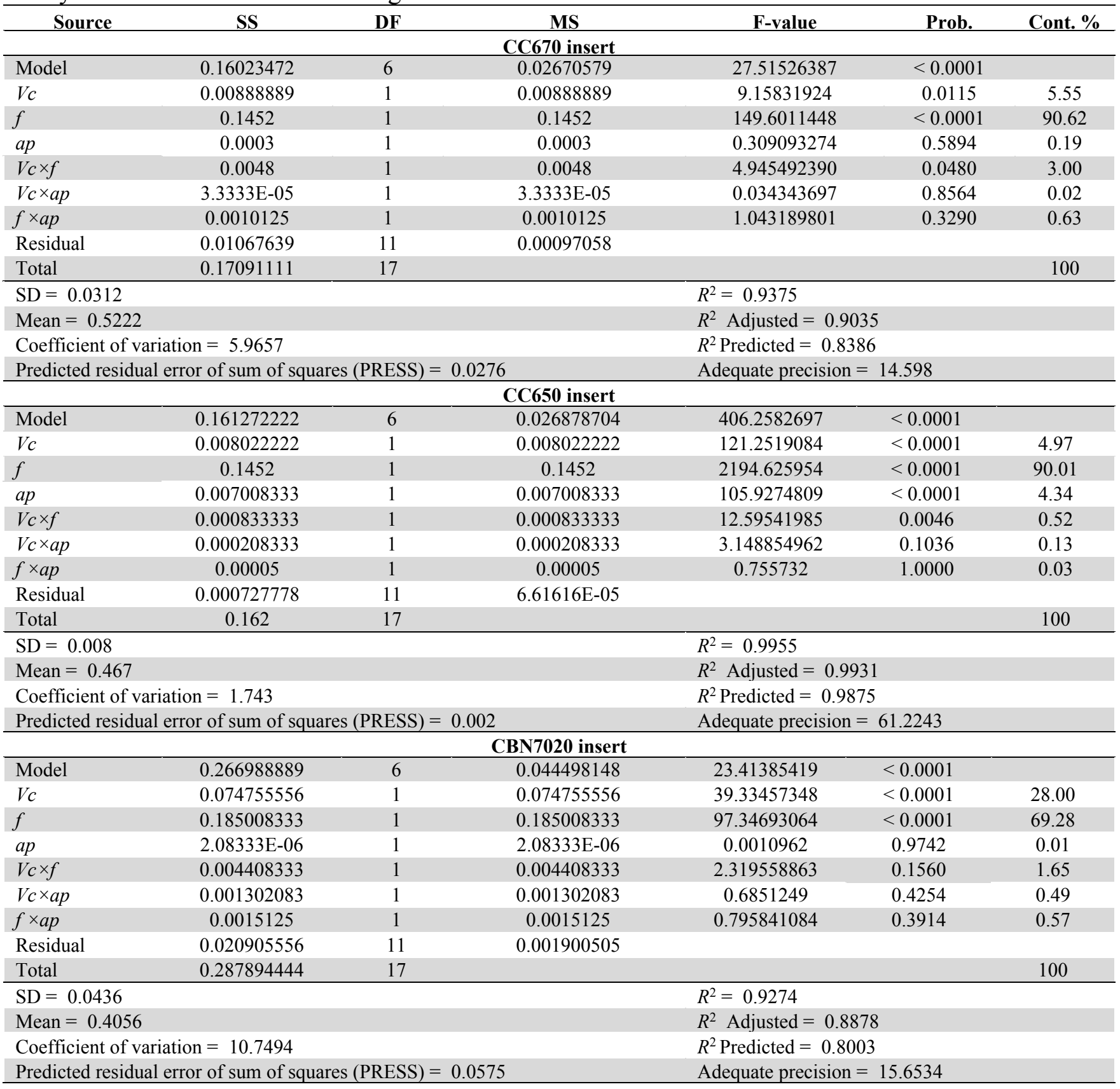

\subsection{Correlations}

The correlation between the cutting factors and measured surface roughness criteria ( $R a$ and $R t)$ are determined from the following multiple linear regression equations (Eqs. (4-8) for three different cutting tools, namely reinforced ceramic CC670, mixed ceramic CC650, and cubic boron nitride CBN7020. The coefficients of determination $\left(R^{2}\right)$ values of developed machinability models have very good correlations between the experimental and predicted values of machinability characteristics. The arithmetic mean roughness for $\left(R a_{\mathrm{CC} 670}, R a_{\mathrm{CC} 650}\right.$ and $\left.R a_{\mathrm{CBN} 7020}\right)$ models are given below in Eqs. (3-5). Heir coefficients of determination $\left(R^{2}\right)$ are $93.75 ; 99.55$ and $92.74 \%$. 
Table 5

Analysis of variance for surface roughness $R t$

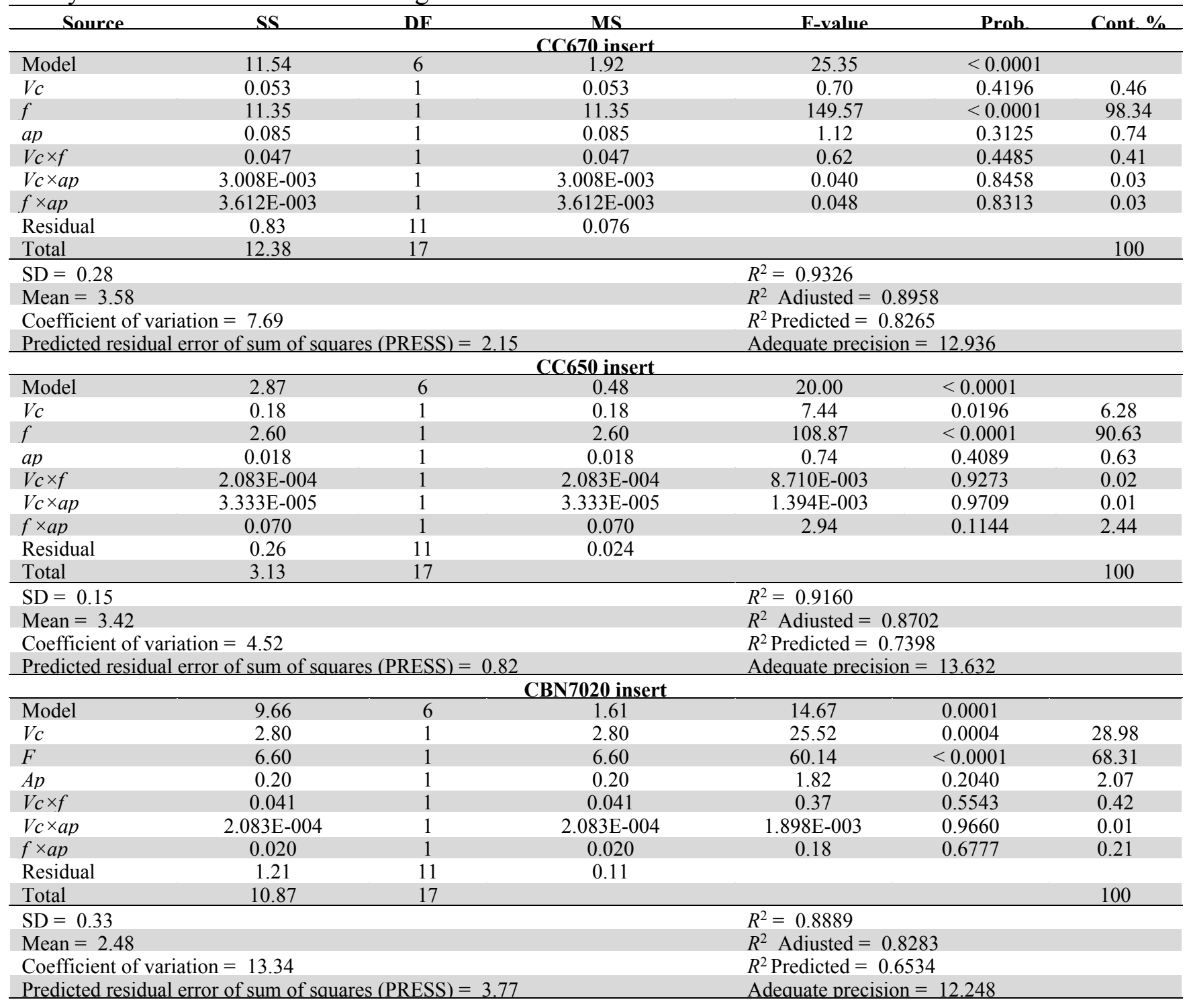

$$
\begin{aligned}
R a_{C C 670}= & 0.0975+0.00115 V c+4.6875 f-0.31388 a p-0.01667 V c \times f \\
& +0.00037 V c \times a p+1.875 f \times a p, \\
R a_{C C 650}= & 0.27722-0.001259 V c+1.70833 f+0.3 a p+0.00694 V c \times f \\
& -0.00092 V c \times a p+2.6577 \times 10^{-15} f \times a p, \\
R a_{C B N 7020}= & 0.62194-0.00337 V c+0.02083 f+0.06944 a p+0.01597 V c \times f \\
& -0.002315 V c \times a p+2.2916 f \times a p .
\end{aligned}
$$

The total roughness model for $\left(R a_{\mathrm{CC} 670}, R a_{\mathrm{CC} 650}\right.$ and $\left.R a_{\mathrm{CBN} 7020}\right)$ models are given below in Eqs. (6-8). Heir coefficients of determination $\left(R^{2}\right)$ are 93.26 ; 91.60 and $88.89 \%$.

$$
\begin{aligned}
R t_{C C 670}= & 0.11806+3.3796 \times 10^{-3} V c+31.0625 f-0.39167 a p-0.0521 V c \times f \\
+ & 3.5185 \times 10^{-3} V c \times a p+3.5416 f \times a p, \\
R t_{C C 650}= & 2.9592-3.009 \times 10^{-3} V c+7.4792 f-1.675 a p-3.4722 V c \times f \\
+ & 3.7037 \times 10^{-4} V c \times a p+15.625 f \times a p, \\
R t_{C B N 7020}= & 1.3555-7.5925 \times 10^{-3} V c+28.3333 f-2.4873 \times 10^{-14} a p-0.0486 V c \times f \\
& +9.2592 \times 10^{-4} V c \times a p-8.3333 f \times a p .
\end{aligned}
$$


Figs. 5-6 show the comparison between the values of the surface roughness criteria $(R a$ and $R t)$ for third cutting tools CC670, CC650 and CBN7020.The insert CBN7020 provides lower values than the both ceramic tools, which translates to a decreased surface roughness with cubic boron nitride CBN7020, because the higher thermal conductivity of CBN tool compared to ceramic tool. For example;

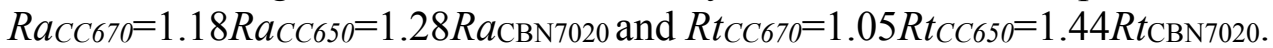

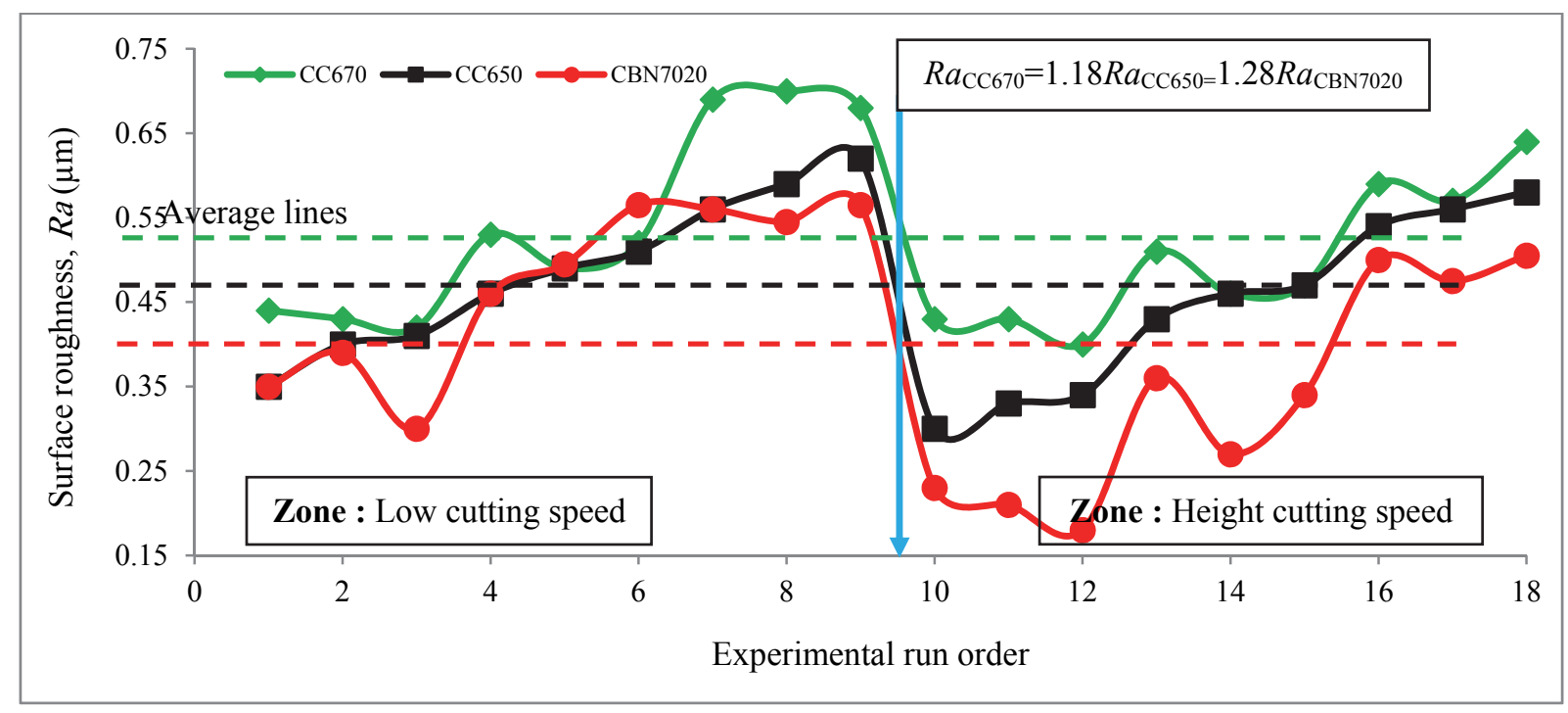

Fig. 5. Comparison between CC670, CC650 and CBN7020 for surface roughness $R a$

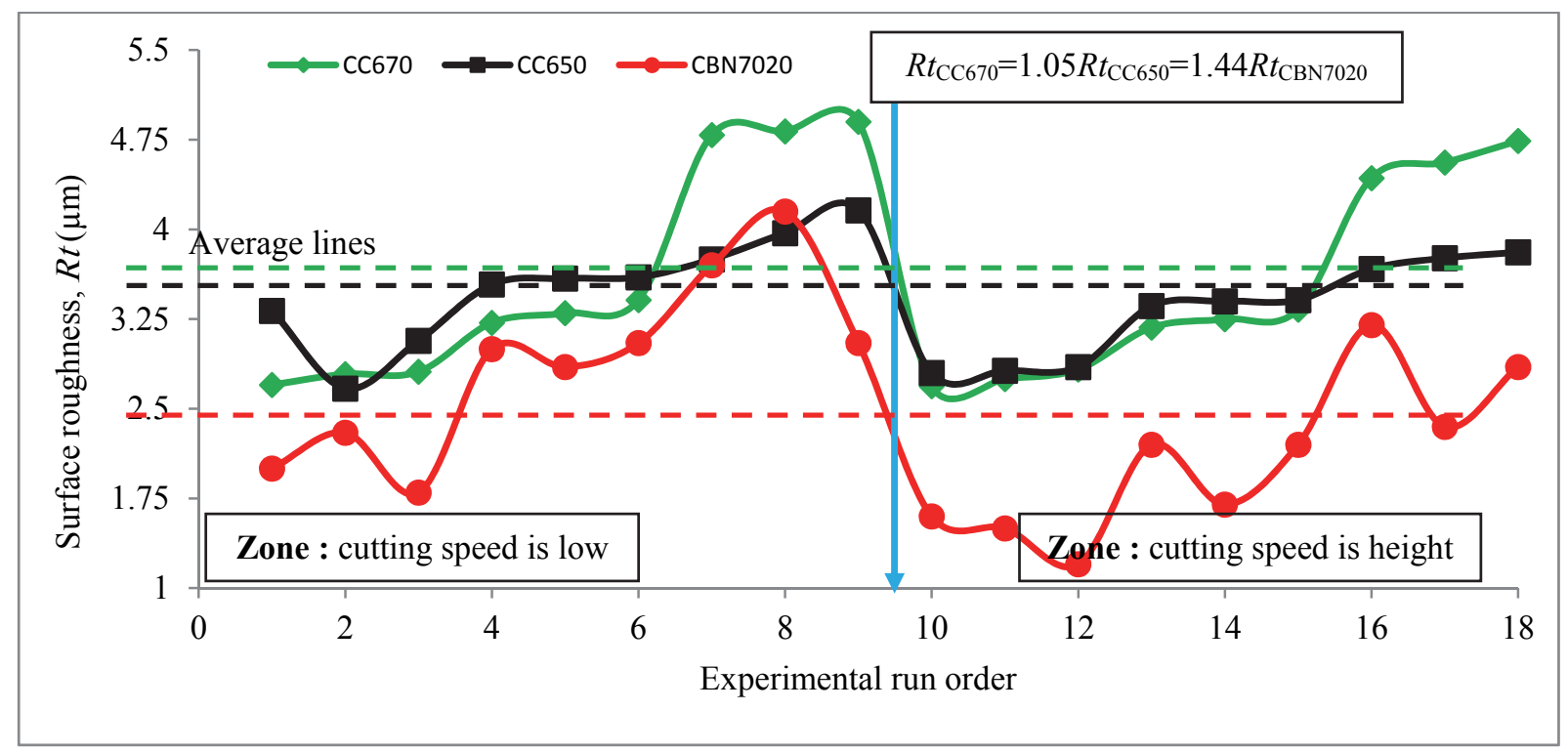

Fig. 6. Comparison between CC670, CC650 and CBN7020 for surface roughness Rt

\subsection{D surface topography}

The representative examples of 3D images of hard turned surfaces are visualized by means of four isometric views. The 3D topographies of the as machined surfaces are shown in Fig. 7. The turned surface topography in Fig. 7 show well-defined peaks and valleys. This is mainly because the process turning uses a single cutting edge with defined geometry to generate helicoid furrow the result of tool shape and helicoids movement tool-workpiece. 


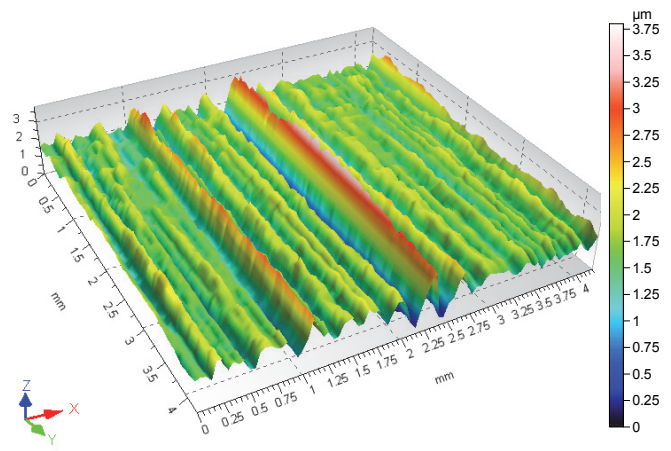

CC650

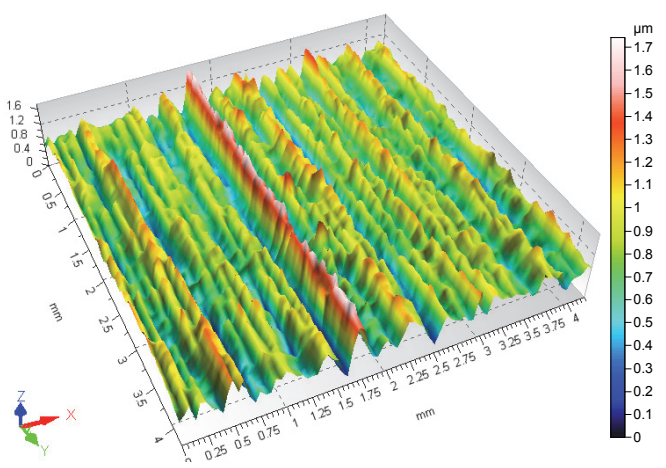

CC670

Fig. 7. 3D surface topography

\subsection{Effect of machining parameters on surface response factors}

In order to investigate the influences of machining parameters on the surface roughness criteria ( $R a$ and $R t$ ), 3D surface graphs are drawn in Figs. 7 and 8. Firstly, Fig. 7 shows the interaction effects of feed rate $(f)$ - cutting speed $(V c)$, depth of cut $(a p)$ - feed rate $(f)$ and depth of cut $(a p)$ - cutting speed $(V c)$ on arithmetic mean roughness $(R a)$ during hard turning of hot work steel using three different cutting tools namely, reinforced ceramic CC670, mixed ceramic CC650 and cubic boron nitride CBN7020. It can be observed from Figs. 7a and $b$ that, for the given cutting speed or depth of cut, the arithmetic mean roughness sharply increases with the increase in feed rate. Fig. 7c shows the estimated response surface for arithmetic mean roughness in relation to depth of cut and cutting speed, while the feed rate is kept at the middle level. As it can be deduced from this figure, the surface roughness $(R a)$ is not statistically significant (Table 5). In general, from the above discussion, Fig. 7 clearly suggests that the surface roughness $R a$ can be minimized by employing lower values of feed rate and higher cutting speed, but the depth of cut has a very weak effect compared to that of the feed rate and cutting speed for all cutting tools. In conclusion, the CBN7020 tool produces a better surface finish than the ceramic cutting tools (CC650 and CC670).

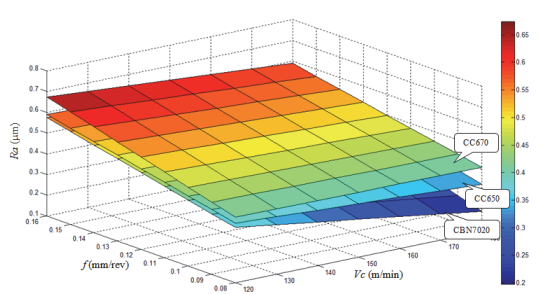

(a)

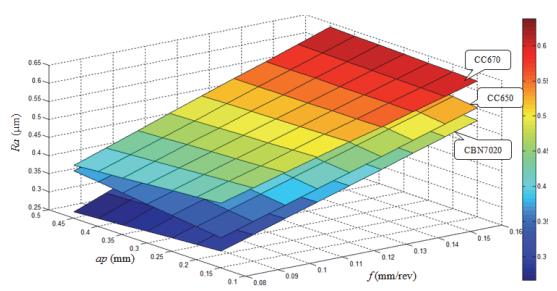

(b)

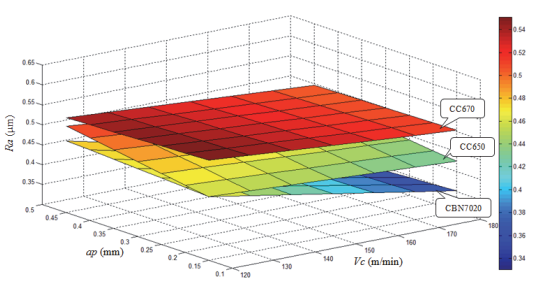

(c)

Fig. 7. Effect of cutting parameters on surface roughness $R a$ (CC670, CC650 and CBN7020)

Finally, Fig. 8a presents the interaction between feed rate and cutting speed while the depth of cut is kept at the middle level. Initially, the total roughness increased by increasing the feed rate. The surface roughness $R t$ is found to be minimal at high cutting speed with low feed rate. This can be explained that with increasing feed rate, leading to vibration and generating more heat and therefore contributing to a higher surface roughness. However, the surface roughness $R t$ decreases sharply with the increase in cutting speed for a given value of feed rate. A comparison study reveals that, the performance of CBN7020 insert is better as compared to both CC650 and CC670 ceramic inserts with reference to surface roughness Rt. Fig. 8b shows the interaction effect between the depth of cut and the feed rate on the total roughness $R t$. From the illustration, it is seen that surface roughness $R t$ increases with an increase in the feed rate. The surface roughness is found to be minimal at all values the depth of cut with low feed rate. Fig. 8c shows the interaction effect between the depth of cut and the cutting speed on the total roughness. From the illustration, it is seen that the total roughness decreases with an increase in the cutting speed, whereas the best surface roughness is observed at a low level of the depth of cut and a high level of the cutting speed. This is due to the fact that, as cutting speed increases, the temperature increases 
at the cutting zone that leads to the softening of material and thus reduces the surface roughness (Suresh et al. 2012). In general, the cubic boron nitride CBN7020 has the better performance compared with ceramic cutting inserts (CC6050 and CC670) for all interaction effects between cutting parameters. This is partly explained by the higher thermal conductivity of $\mathrm{CBN}$ tool compared to ceramic tool.

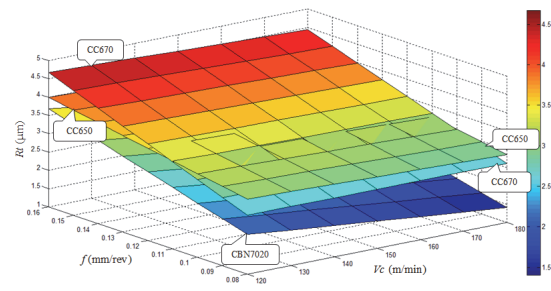

(a)

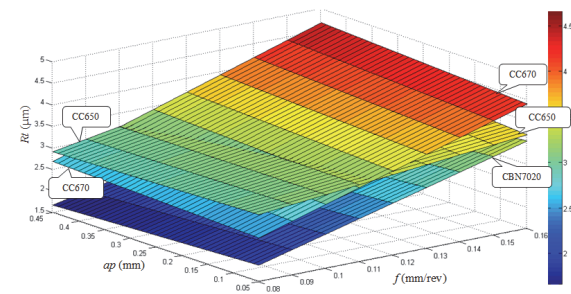

(b)

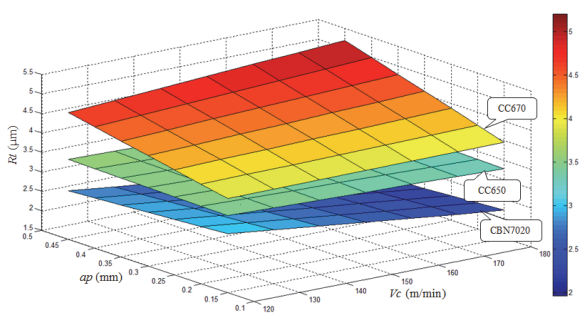

(c)

Fig. 8. Effect of cutting parameters on surface roughness Rt (CC670, CC650 and CBN7020)

\section{Conclusions}

In the present paper, an investigative study on machinability aspects of arithmetic mean roughness $(R a)$ and total roughness $(R t)$ has been carried out during hard turning of AISI H11 hot work steel with three different cutting tools, namely reinforced ceramic CC670, mixed ceramic CC650, and cubic boron nitride CBN7020. The response surface methodology (RSM) based mathematical models were developed to analyze the effects of cutting speed, feed rate and depth of cut on machinability. The experiments were planned according to Taguchi's $\mathrm{L}_{18}$ factorial design and the adequacy of the models was tested through analysis of variance (ANOVA). Based on the experimental results and parametric analysis, the following conclusions are drawn.

1. The result of ANOVA proved that the multiple linear regression models allow prediction of surface roughness parameter with a $95 \%$ confident interval.

2. The surface roughness criteria ( $R a$ and $R t$ ) are highly sensitive to feed rate in case of hard turning with CC650 and CC670 ceramic inserts as compared to CBN7020 insert. The surface roughness criteria ( $R a$ and $R \mathrm{t}$ ) increases with increase in cutting speed in case of CC650 and CBN7020 inserts machining, while the surface roughness criteria increases at $180 \mathrm{~m} / \mathrm{min}$ cutting speed in case of CC670 machining. On the other hand, the surface roughness is minimal at lower value of feed rate and higher value of cutting speed for all cutting tools.

3. In general, cubic boron nitride CBN7020 has the better performance compared with ceramic cutting inserts (CC6050 and CC670), in particular the surface roughness of the workpiece. Ratios mean value for surface roughness criteria $R a_{\mathrm{CC} 670}=1.18 R a_{\mathrm{CC} 650}=1.28 R a_{\mathrm{CBN} 7020}$ and

$\operatorname{Rt}_{C C 670}=1.05 R t_{C C 650}=1.44 R t_{\mathrm{CBN} 7020}$.

\section{References}

Aouici, H., Bouchelaghem, H., Yallese, MA., Elbah, M., \& Fnides, B. (2014). Machinability investigation in hard turning of AISI D3 cold work steel with ceramic tool using response surface methodology. The International Journal of Advanced Manufacturing Technology, 73, 1775-1788.

Aouici, H., Yallese, MA., Chaoui, K., Mabrouki, T., \& Rigal, JF. (2012) Analysis of surface roughness and cutting force components in hard turning with $\mathrm{CBN}$ tool: Prediction model and cutting conditions optimization. Measurement, 45(3), 344-353.

Asiltürk, I., \& Neseli, S. (2011). Multi response optimisation of CNC turning parameters via Taguchi method-based response surface analysis. Measurement, 45(4), 785-794.

Azizi, MW., Belhadi, S., Yallese MA., Mabrouki, T., \& Riga, JF. (2012). Surface roughness and cutting forces modeling for optimization of machining condition in finish hard turning of AISI 52100 steel. Journal of Mechanical Science and Technology, 25(12), 4105-4114. 
Bouchelaghem, H., Yallese, MA., Amirat, A., Mabrouki, T., Rigal, JF. (2010). Experimental investigation and performance analyses of CBN insert in hard turning of cold work tool steel (D3). Machining Science and Technology, 14(4), 471-501.

Çiçek, A., Kara, F., Kivak, T., \& Ekici, E. (2013). Evaluation of machinability of hardened and cryotreated AISI H13 hot work tool steel with ceramic inserts. International Journal of Refractory Metals and Hard Materials, 41, 461-469.

Davim, J. P., \& Figueira, L. (2007). Comparative evaluation of conventional and wiper ceramic tools on cutting forces, surface roughness, and tool wear in hard turning AISI D2 steel. Proceedings of the Institution of Mechanical Engineers, Part B: Journal of Engineering Manufacture, 221(4), 625-633.

Elbah, M., Yallese, M. A., Aouici, H., Mabrouki, T., \& Rigal, J. F. (2013). Comparative assessment of wiper and conventional ceramic tools on surface roughness in hard turning AISI 4140 steel. Measurement, 46(9), 3041-3056.

Federico, M,A., Reginaldo, T.C., \& Lincoln, C.B. (2008). Turning hardened steel using coated carbide at high cutting speeds. Journal Brazilian Society of Mechanical Sciences and Engineering, 30(2), 104-109.

Fnides, B., Boutabba, S., Fnides, M., Aouici, H., \& Yallese, M.A. (2013). Cutting tools flank wear and productivity investigation in straight turning of X38CrMoV5-1 (50 HRC). International Journal of Applied Engineering and Technology, 3(1), 1-10.

Fnides, B., Yallese, M.A., Mabrouki, T., \& Rigal, J.F. (2011). Application of response surface methodology for determining cutting force model in turning hardened AISI H11 hot work tool steel. Sadhana, 36(1), 109-123.

Gaitonde, V.N., Karnik, S.R., Figueira, L., \& Davim, J.P. (2009). Analysis of machinability during hard turning of cold work tool steel (type: AISI D2). Materials Manufacture Processes Taylor Francis, 24(12), 1373-1382.

Horng, J. T., Liu, N. M., \& Chiang, K. T. (2008). Investigating the machinability evaluation of Hadfield steel in the hard turning with $\mathrm{Al} 2 \mathrm{O} 3 / \mathrm{TiC}$ mixed ceramic tool based on the response surface methodology. Journal of materials processing technology, 208(1), 532-541.

Kribes, N., Hessainia, Z., Yallese, MA., \& Ouelaa, N. (2012). Statistical analysis of surface roughness by design experiments in hard turning. Mechanika, 18(5), 605-611.

Lima, J.G., Ávila, R.F., Abrao, A.M., Faustino, M., Davim, J.P. (2005). Hard turning: AISI 4340 high strength alloy steel and AISI D2 cold work tool steel. Journal of Materials Processing Technology, 169(3), 388-395.

Mahfoudi, F., List, G., Molinari, A., Moufki, A., \& Boulanouar, L. (2008). High speed turning for hard material with PCBN inserts: tool wear analysis. International Journal of Machining and Machinability of Materials, 3(1/2), 62-79.

Okada, M., Hosokawa, A., Tanaka, R., \& Ueda, T. (2011). Cutting performance of PVD-coated carbide and CBN tools in hardmilling. International Journal of Machine Tools and Manufacture, 51(2), 127132.

Sahin, Y., \& Motorcu, A. R. (2008). Surface roughness model in machining hardened steel with cubic boron nitride cutting tool. International Journal of Refractory Metals and Hard Materials, 26(2), 8490.

Sales, W. F., Costa, L. A., Santos, S. C., Diniz, A. E., Bonney, J., \& Ezugwu, E. O. (2009). Performance of coated, cemented carbide, mixed-ceramic and PCBN-H tools when turning W320 steel. The International Journal of Advanced Manufacturing Technology, 41(7-8), 660-669.

Suresh, R., Basavarajappa, S., \& Samuel, G. L. (2012). Some studies on hard turning of AISI 4340 steel using multilayer coated carbide tool. Measurement,45(7), 1872-1884.

Thiele, J. D., \& Melkote, S. N. (1999). Effect of cutting edge geometry and workpiece hardness on surface generation in the finish hard turning of AISI 52100 steel. Journal of Materials Processing Technology, 94(2), 216-226. 